\title{
CONTAMINAÇÃO ENDÓGENA POR ASPERGILLUS SPP. EM MILHO PÓS-COLHEITA NO ESTADO DO PARANÁ ${ }^{1}$
}

\author{
ANTONIO XAVIER DE FARIAS ${ }^{2}$, CHARLES FREDERICK ROBBS ${ }^{3}$, ANNA MARIA BITTENCOURT ${ }^{4}$, \\ PAUL MARIUS ANDERSEN ${ }^{5}$ e TÂNIA BARRETTO SIMÕES CORRÊA ${ }^{4}$
}

\begin{abstract}
RESUMO - Sessenta amostras de milho pós-colheita foram avaliadas quanto à contaminação fúngica endógena e o potencial toxígeno de espécies do gênero Aspergillus e seus teleomorfos. Quarenta grãos aparentemente sadios de cada amostra foram desinfestados em $\mathrm{NaClO}$ e incubados em câmara úmida a $25 \pm 1^{\circ} \mathrm{C}$ para exteriorização dos fungos, que posteriormente foram isolados em ágar Czapek-Dox. Foram identificadas as espécies Aspergillus flavus, A. parasiticus, Eurotium amstelodami e E. chevalieri. O potencial toxígeno dos fungos A. flavus e A. parasiticus foi avaliado quanto à síntese de aflatoxinas em meio ágar-coco. Espécies do gênero Eurotium foram avaliadas quanto à síntese de esterigmatocistina, nos meios ágar-amendoim e trigo triturado. A porcentagem de grãos contaminados variou entre 0 e $100 \%$, prevalecendo os gêneros Aspergillus, Penicillium e Fusarium. A espécie predominante foi a A. flavus (64\%), seguida por E. amstelodami (19\%), E. chevalieri (10\%) e A. parasiticus (7\%). A partir de 109 isolados de A. flavus, evidenciou-se que 73 isolados sintetizaram aflatoxinas $\mathrm{B}_{1}$ e $\mathrm{B}_{2}, 20$ sintetizaram $B_{1}$, sete sintetizaram $B_{1}$ e $G_{1}$, três sintetizaram $B_{1}, B_{2}$ e $G_{1}$ e em seis não foi detectada a síntese de aflatoxina. A síntese de esterigmatocistina pelas espécies E. amstelodami e E. chevalieri não foi detectada.
\end{abstract}

Termos para indexação: aflatoxinas, teleomorfos, potencial toxígeno, fungos toxígenos, Zea mays.

\section{ENDOGENOUS ASPERGILLUS SPP. CONTAMINATION OF POSTHARVEST CORN IN PARANÁ STATE, BRAZIL}

\begin{abstract}
Sixty post-harvested samples of maize kernels from three regions of the Paraná State, Brazil, were evaluated concerning endogenous fungi contamination and toxigenic potential of Aspergillus spp. and some of their teleomorfs. Forty apparently healthy kernels were selected from each sample, disinfested with $\mathrm{NaClO}$ and incubated at $25 \pm 1^{\circ} \mathrm{C}$ for fungal growth. Fungus species were isolated in Czapek-Dox agar plates. The species Aspergillus flavus, A. parasiticus, Eurotium amstelodami and E. chevalieri were identified. The toxigenic potential of Aspergillus species were analyzed in coconut agar medium. Eurotium spp. were evaluated for their metabolics in peanut agar medium and in wheat grits. The kernel contamination varied from 0 to $100 \%$ and the prevalent genera detected were Aspergillus, Penicillium and Fusarium. A. flavus was the predominant species (64\%), followed by E. amstelodami (19\%), E. chevalieri (10\%) and A. parasiticus (7\%). From 109 A. flavus species isolated, 73 strains synthesized aflatoxins $B_{1}$ and $B_{2}, 20$ synthesized $B_{1}$, seven synthesized $B_{1}$ and $G_{1}$, three synthesized $B_{1}, B_{2}$ and $G_{1}$ and in six strains aflatoxin production was not detected. All A. parasiticus species produced, simultaneously, $\mathrm{B}_{1}, \mathrm{~B}_{2}, \mathrm{G}_{1}$ and $\mathrm{G}_{2}$. Sterigmatocystin synthesis was not detected in any condition by E. amstelodami and E. chevalieri.
\end{abstract}

Index terms: aflatoxins, teleomorphs, toxigenic potential, toxigenic fungi, Zea mays.

${ }^{1}$ Aceito para publicação em 10 de maio de 1999.

${ }^{2}$ Biól., M.Sc., Embrapa-Centro Nacional de Pesquisa de Tecnologia Agroindustrial de Alimentos (CTAA), Av. das Américas 29501, CEP 23020-470 Rio de Janeiro, RJ. E-mail: antxafar@ctaa.embrapa.br

${ }^{3}$ Eng. Agrôn., Dr., Embrapa-CTAA.

${ }^{4}$ Eng. Quím., M.Sc., Embrapa-CTAA. E-mail: tania@ctaa.embrapa.br

${ }^{5}$ Eng. Quím., UFRJ/Embrapa-CTAA. E-mail: andersen@ctaa.embrapa.br

\section{INTRODUÇÃO}

A cultura do milho (Zea mays L.) na agricultura brasileira é de grande importância econômica, sendo prioritária na política agrícola do país por ser responsável pela maior utilização de mão-de-obra no setor rural, ocupando a maior área cultivada, com ampla distribuição de norte a sul do país (Kibuuka, 
1993) e representando $43 \%$ da produção brasileira de grãos. As regiões Sul e Sudeste são as responsáveis por $80 \%$ da produção. O Estado do Paraná, principal produtor nacional desse grão, participa com aproximadamente $22 \%$ desse total, com uma safra de 7,7 toneladas no ano de 1996, segundo dados do IBGE (1997).

Esse cereal pode estar sujeito à contaminação por uma microbiota fúngica diversa durante a formação dos grãos, na colheita, no transporte e no armazenamento, com redução da qualidade sanitária, física e nutricional dos grãos e seus derivados e perdas do produto. Várias espécies desses fungos, em condições favoráveis, podem produzir metabólitos tóxicos, as micotoxinas, ocasionando problemas de saúde pública e animal (Lázzari, 1993).

A identificação das espécies fúngicas contaminantes (Pozzi, 1993) é um importante sinalizador quanto à presença de micotoxinas nos substratos, e indica o caminho para prevenir a sua produção. Entretanto, Ranjan \& Sinha (1991) afirmam que o isolamento e a identificação desses fungos nem sempre estão ligados à detecção de micotoxinas no produto analisado, considerando que existem cepas dentro de uma mesma espécie que não possuem a capacidade para síntese de micotoxinas, e sugerem a avaliação do potencial de síntese de metabólitos tóxicos por esses fungos.

As micotoxinas são metabólitos secundários, sintetizados no final da fase exponencial de crescimento de alguns fungos. Alguns desses compostos desenvolvem atividade mutagênica, carcinogênica e teratogênica. As aflatoxinas são substâncias do grupo das bisfuranocumarinas produzidas principalmente por Aspergillus flavus e A. parasiticus. Existem várias substâncias conhecidas nesse grupo. As mais encontradas em diversos produtos agrícolas e seus derivados são as aflatoxinas $\mathrm{B}_{1}, \mathrm{~B}_{2}, \mathrm{G}_{1}$ e $\mathrm{G}_{2}$; a $\mathrm{B}_{1}$ é a mais tóxica. A esterigmatocistina é um precursor da síntese de aflatoxina $\mathrm{B}_{1}$ e é um produto final de sua rota metabólica. Caracteriza-se por possuir um anel dehidrofurobensofurano acoplado a uma xantona, sendo produzida principalmente por A. versicolor (Jay, 1996).

Este trabalho teve como objetivos a determinação do nível de contaminação endógena, o isolamento e a identificação de espécies do gênero Aspergillus e seus teleomorfos com potencial para síntese de aflatoxinas $\left(\mathrm{B}_{1}, \mathrm{~B}_{2}, \mathrm{G}_{1}\right.$ e $\left.\mathrm{G}_{2}\right)$ e esterigmatocistina, presentes na microbiota de grãos de milho pós-colheita produzido no Estado do Paraná.

\section{MATERIAL E MÉTODOS}

Foram avaliadas 60 amostras de milho, provenientes de três localidades do Estado do Paraná (Andirá, Apucarana e Sarandi), fornecidas por indústrias cooperativadas da Associação das Indústrias Moageiras de Milho (ABIMILHO), coletadas segundo a metodologia recomendada por Fonseca (1991) e adotada pelo Ministério da Agricultura para amostragem em grãos a granel para análises de micotoxinas.

Foram selecionados 40 grãos de cada amostra (Almenar et al., 1980), aparentemente sadios. Estes foram tratados com solução comercial de hipoclorito de sódio a $2 \%$ de cloro livre residual, durante dois minutos (Sinha, 1990), lavados três vezes em água esterilizada, e transferidos assepticamente para placas de Petri esterilizadas, com $150 \mathrm{~mm}$ de diâmetro, contendo um disco de espuma sintética umedecido com água destilada esterilizada. A incubação foi realizada em estufa BOD a $25 \pm 1^{\circ} \mathrm{C}$ por um período de 7 a 14 dias até a exteriorização e desenvolvimento dos fungos (Farias, 1996). A contagem dos grãos colonizados por fungos foi realizada com auxílio de microscópio estereoscópico.

$\mathrm{O}$ isolamento de cada cultura fúngica foi realizado por meio da técnica de transferência sucessiva de conídios em ágar Czapeck-Dox. As culturas foram identificadas como pertencentes ao gênero Aspergillus (Pitt, 1991), Penicillium (Klich \& Pitt, 1994) e Fusarium (Samson et al., 1995).

\section{Identificação das espécies do gênero Aspergillus e seus teleomorfos}

Os isolados do gênero Aspergillus com colorações verde e verde-amarelado foram repicados em ágar Aspergillus Differential Medium (ADM) (Bothast \& Fennell, 1974), para seleção das espécies A. flavus e A. parasiticus, que não esporulam nesse meio de cultivo e produzem pigmentação alaranjada no reverso das colônias. Posteriormente, essas espécies foram identificadas em ágar Czapeck-Dox, considerando a predominância da disposição das métulas nas vesículas conidiais (uni ou bisseriadas) e a ornamentação dos conídios (Klich $\&$ Pitt, 1994). As culturas negativas para o teste em ADM e as demais culturas de coloração verde do gênero Aspergillus com formação de cleistotécios foram inocula- 
das em meio "Czapeck yeast extract agar" a $25^{\circ} \mathrm{C}$ e $37^{\circ} \mathrm{C}$, e em "malt extract agar" a $25^{\circ} \mathrm{C}$. As observações dos caracteres (macroscópicos e microscópicos) foram realizadas com 7 e 14 dias de incubação e interpretadas com uso das chaves de identificação de Klich \& Pitt (1994), a fim de selecionar as espécies Eurotium amstelodami e E. chevalieri.

\section{Avaliação do potencial toxígeno dos fungos seleciona-} dos

Os isolados de A. flavus e A. parasiticus foram inoculados em um ponto central na placa de ágar-coco, segundo Lin \& Dianese (1976), e incubados em estufa BOD a $25 \pm 1^{\circ} \mathrm{C}$, durante 7 dias. As colônias desenvolvidas e o meio ao seu redor foram transferidos para cápsulas de porcelana e macerados com a adição de $30 \mathrm{~mL}$ de clorofórmio. Os extratos obtidos foram filtrados em papel de filtro, concentrados em Rotavapor Buchi e ressuspendidos em $20 \mu \mathrm{L}$ de clorofórmio. A cromatografia em camada delgada (CCD) foi desenvolvida em câmara previamente saturada com o sistema de solventes constituído de tolueno/acetato de etila/clorofórmio/ácido fórmico (70:50:50:20) (Cruz et al.,1992), utilizando-se os padrões de aflatoxinas $\mathrm{B}_{1}, \mathrm{~B}_{2}, \mathrm{G}_{1}$ e $\mathrm{G}_{2}$ da Sigma Company. A confirmação da identidade das aflatoxinas e o preparo dos padrões foram realizados conforme a Association of Official Analytical Chemists (1995).

Os isolados de Eurotium amstelodami e E. chevalieri foram avaliados quanto à síntese de esterigmatocistina, em duas condições: a) em um ponto central em ágar-amendoim (Bastos, 1979), seguido de incubação por 20 dias em estufa BOD a $28^{\circ} \mathrm{C}$. As colônias desenvolvidas e o meio ao seu redor foram macerados com $30 \mathrm{~mL}$ de clorofórmio, submetidos a tratamento em banho-maria com ultra-som por $15 \mathrm{~min}$, filtrados em papel de filtro, concentrados em Rotavapor e ressuspendidos em $1 \mathrm{~mL}$ de clorofórmio (Farias, 1996); b) das culturas em trigo triturado esterilizado, seguido de incubação por 20 dias em estufa BOD a $28^{\circ} \mathrm{C}$. Os meios colonizados foram macerados com acetonitrila/cloreto de potássio 4\% (90:10), submetidos a tratamento em banho-maria com ultra-som por $15 \mathrm{~min}$, filtrados em papel de filtro, extraídos por partição com hexano e clorofórmio e concentrados em rotavapor (Farias, 1996). Os extratos brutos foram ressuspendidos em $2 \mathrm{~mL}$ de metanol e $200 \mu \mathrm{L}$ desta solução foram submetidos ao clean up em cartuchos Sep Pak $\mathrm{C}_{18}$, utilizando como primeiro eluente $3 \mathrm{~mL}$ de metanol:água (50:50), e como segundo eluente $10 \mathrm{~mL}$ de solução metanol:água (60:40). Este segundo eluato foi filtrado em membrana Millipore de 0,45 $\mu \mathrm{m}$ (Schmidt et al., 1981).
Os extratos obtidos nas condições acima (a e b) e o padrão de esterigmatocistina (Sigma Company) foram cromatografados em camada delgada, com o sistema de solventes benzeno/ácido acético/metanol (90:5:5), conforme Association of Official Analytical Chemists (1995). Os mesmos extratos foram também submetidos $(20 \mu \mathrm{L}$ de cada um) a cromatografia líquida de alta eficiência (CLAE), com coluna Novapak $\mathrm{C}_{18}$, utilizando-se a fase móvel metanol/água (65:35).

\section{RESULTADOS E DISCUSSÃO}

O desenvolvimento de fungos nos grãos revelou uma porcentagem de grãos com colonização fúngica, variando entre 0 a $100 \%$ (Fig. 1), prevalecendo Aspergillus, Penicillium e Fusarium, os três gêneros mais importantes envolvidos na produção de micotoxinas. Asevedo et al. (1994), que pesquisaram a microbiota fúngica e espécies produtoras de aflatoxinas em 90 amostras de milho estocados em diferentes regiões do Brasil, também isolaram os seguintes gêneros de fungos filamentosos apresentados em ordem decrescente de ocorrência: Aspergillus (72,2\%), Penicillium (67,7\%), Fusarium (62,2\%). Adebajo et al. (1994) investigando a microbiota fúngica de milho e produtos à base de milho, também verificaram que os gêneros Aspergillus, Penicillium e Fusarium eram predominantes. Já Castro et al. (1995), estudando a microbiota em milho coletado em diferentes localidades do Estado de São Paulo, verificaram que os gêneros predominantes eram Fusarium e Penicillium, e o gênero Aspergillus foi o de menor frequiência.

Através da identificação como espécie, em 169 isolados do gênero Aspergillus, o fungo A. flavus

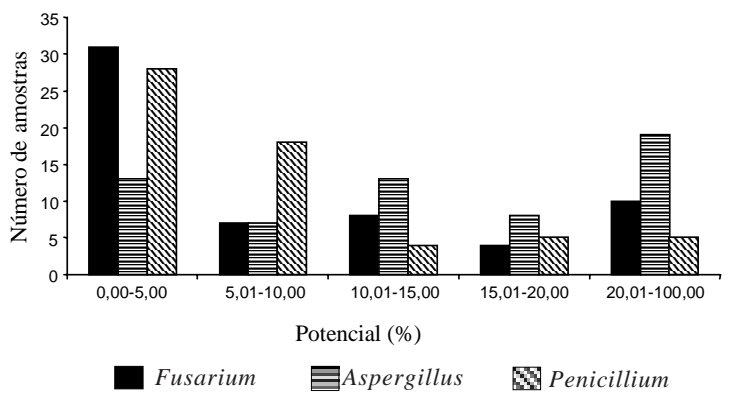

FIG. 1. Potencial de contaminação em 60 amostras de milho pós-colheita do Estado do Paraná.

Pesq. agropec. bras., Brasília, v.35, n.3, p.617-621, mar. 2000 
foi predominante (64\%), seguido por E. amstelodami (19\%), E. chevalieiri (10\%) e A. parasiticus $(7 \%)$ (Fig. 2). Asevedo et al. (1994) também verificaram a predominância de A. flavus $(36,6 \%)$ seguido das espécies A. oryzae $(9,9 \%)$, A. parasiticus $(6,6 \%)$, A. ochraceus $(6,6 \%)$.

A avaliação do potencial toxígeno em 109 isolados da espécie $A$. flavus demonstrou que 73 isolados $(67 \%)$ possuíam potencial para síntese de aflatoxinas $\mathrm{B}_{1}$ e $\mathrm{B}_{2}, 20$ (18\%) produziram aflatoxina $\mathrm{B}_{1}$, enquanto as aflatoxinas $\mathrm{B}_{1}$ e $\mathrm{G}_{1}$ foram sintetizadas por sete isolados $(6 \%)$, e as aflatoxinas $\mathrm{B}_{1}, \mathrm{~B}_{2}$, $\mathrm{G}_{1}$, por três isolados (3\%), e seis isolados $(6 \%)$ desta espécie não apresentaram potencial para síntese de aflatoxinas. Todos os 11 isolados da espécie A. parasiticus demonstraram potencial para síntese de aflatoxinas $\mathrm{B}_{1}, \mathrm{~B}_{2}, \mathrm{G}_{1}$ e $\mathrm{G}_{2}$. Os dados obtidos com a avaliação do potencial toxígeno dos isolados fúngicos das espécies $A$. flavus e A. parasiticus evidenciaram a variabilidade de cepas existentes quanto à síntese de metabólitos tóxicos dentro de uma mesma espécie. Também a capacidade de A. parasiticus sintetizar simultaneamente as quatro principais aflatoxinas $\left(B_{1}, B_{2}, G_{1}\right.$ e $\left.G_{2}\right)$ foi registrada. Esses resultados acham-se coerentes com os encontrados por Ranjan \& Sinha (1991), que, estudando o potencial toxígeno de 385 isolados de $A$. flavus, verificaram que $23 \%$ sintetizaram aflatoxina $B_{1}, 17 \%$ produziam $B_{1}$ e $B_{2}$, sendo que as aflatoxinas $B_{1}, B_{2} e_{2}$ foram sintetizadas por $8 \%$ dos isolados. Asevedo et al. (1994) também relataram, em seus estudos, que isolados de $A$. flavus eram toxígenos e produziram as aflatoxinas $\mathrm{B}_{1}$, ou $\mathrm{B}_{1}$ e $\mathrm{B}_{2}$, enquanto todas as cepas testadas de $A$. parasiticus produziram as aflatoxinas $\mathrm{B}_{1}, \mathrm{~B}_{2}, \mathrm{G}_{1}$ e $\mathrm{G}_{2}$.

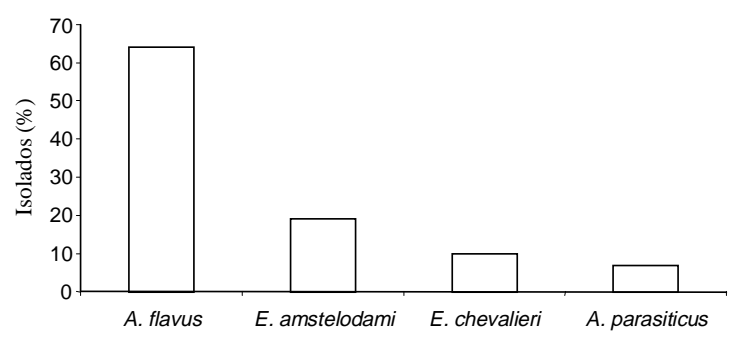

FIG. 2. Porcentagem de isolados identificados em espécies do gênero Aspergillus e seus teleomorfos.
A síntese da micotoxina esterigmatocistina pelas espécies E. amstelodami e E. chevalieri não foi detectada nas duas condições experimentais desenvolvidas (cultivo e metodologia analítica). Os estudos de El-Kady et al. (1994), Smith \& Moss (1985), Singh et al. (1991) e mais recentemente de Frisvad \& Thrane (1995), referiram-se a essas espécies como não produtoras deste metabólito. A não-detecção deste metabólito, nas condições experimentais deste trabalho, pode ser atribuída às condições de cultivo não favoráveis, aos isolados, por não possuírem potencial para síntese de esterigmatocistina e à produção desta micotoxina em níveis não detectáveis.

$\mathrm{O}$ isolamento das espécies E. amstelodami e E. chevalieri, consideradas xerofílicas, em grãos em que o teor de umidade está intimamente ligado à manutenção da qualidade, é um fator relevante, considerando que esses microrganismos em suas reações metabólicas produzem água, favorecendo a deterioração dos grãos e o desenvolvimento de outras espécies fúngicas contaminantes, segundo Sauer et al. (1982) e Valladares (1985).

\section{CONCLUSÕES}

1. Os grãos de milho aparentemente sadios podem apresentar contaminação por fungos com potencial toxígeno.

2. É evidenciada, quanto ao potencial de síntese de micotoxinas, a variabilidade entre cepas da mesma espécie de A. flavus.

3. É confirmada a habilidade das espécies de A. parasiticus de sintetizar simultaneamente as aflatoxinas $\mathrm{B}_{1}, \mathrm{~B}_{2}, \mathrm{G}_{1}$ e $\mathrm{G}_{2}$.

\section{REFERÊNCIAS}

ADEBAJO, L.O.; IDOWU, A.A.; ADESANYA, O.O. Mycoflora, and mycotoxins production in Nigerian corn and corn-based snacks. Mycopathologia, Dordrecht, v.126, p.183-192, 1994.

ALMENAR, V.S.; LUMBRERAS, A.S.; HABA, J.H.; GIMÉNEZ, E.H. Contenido de afs y Aspergillus flavus en maíz almacenado en silos comerciales. Revista de Agroquímica y Tecnología de Alimentos, Valencia, v.20, n.3, p.371-380, 1980. 
ASEVEDO, I.G.; GAMBALE, W.; CORRÊA, B.; PAULA, C.R.; ALMEIDA, R.M.A.; SOUZA, V.M. Mycoflora and aflatoxigenic species of Aspergillus spp. isolated from stored maize. Revista de Microbiologia, São Paulo, v.25, n.1, p.46-50, 1994.

ASSOCIATION OF OFFICIAL ANALYTICAL CHEMISTS. Official methods of analysis. 15.ed. Arlington, 1995. p.1-49.

BASTOS, S.T.G. Método rápido para detecção da produção de ocratoxina e esterigmatocistina por Aspergillus spp. em meios de ágar. Brasília : Universidade de Brasília, 1979. 77p. Tese de Mestrado.

BOTHAST, R.J.; FENNELL, D.I. A medium for rapid identification and enumeration of Aspergillus flavus and related organisms. Mycologia, New York, v.66, p.365-369, 1974.

CASTRO, M.F.P.; SOARES, L.M.V.; FURLANI, R.P.Z Mycoflora, aflatoxigenic species and mycotoxins in freshly harvested corn (Zea mays L.): a preliminary study. Revista de Microbiologia, São Paulo, v.26, n.4, p.289-295, 1995 .

CRUZ, L.C.H. da; CAMPOS, S.G. de; ROSA, C.A. da R. Aplicação do ágar-coco como meio diferencial para o isolamento de fungos citrininogênicos. Arquivos da Universidade Federal Rural do Rio de Janeiro, Itaguaí, v.15, n.1, p.61-64, 1992.

EL-KADY, I.; EL-MARAGHY, S.; ZOHRI, A. Mycotoxin producing potencial of some isolates of Aspergillus flavus and Eurotium groups from meat products. Microbiological Research, Assint, v.149, p.297307, 1994

FARIAS, A.X. Contaminação endógena por Aspergillus spp. e seus teleomorfos com potencial toxígeno em milho pós-colheita do estado do Paraná. Itaguaí : Universidade Federal Rural do Rio de Janeiro, 1996. 52p. Tese de Mestrado.

FONSECA, H. Sistema de amostragem para análise de aflatoxinas em grãos. Revista de Microbiologia, São Paulo, v.21, n.2, p.66-70, 1991.

FRISVAD, J.C.; THRANE, U. Mycotoxin production by food-borne fungi. In: SAMSON, R.A.; HOEKSTRA, E.S.; FRISVAD, J.C.; FILTENBORG, O. (Eds.) Introduction to food-borne fungi. 4.ed. Baarn : Centralalbureau voor Schimmelcultures, 1995. p.251260.

IBGE (Rio de Janeiro, RJ). Levantamento sistemático da produção agrícola. Disponível: URL: http://www.ibge.gov.br/sidra.htm. Consultado em 24 jun. 1997.

JAY, M.J. Modern food microbiology: mycotoxins. 5.ed. New York : Chapman and Hall, 1996. p.595-611.

KIBUUKA, G.K. Efeito da umidade e tempo de condicionamento nas características tecnológicas de milho branco var. BR 451. Campinas : UNICAMP, 1993. 268p. Tese de Doutorado.

KLICH, M.A.; PITT, J.I. A laboratory guide to the common Aspergillus species and their teleomorphs. North Wales : CSIRO-Division of Food Processing, 1994. 116p.

LÁZZARI, A.F. Umidade, fungos e micotoxinas na qualidade de sementes, grãos e rações. Curitiba : Pallotti, 1993. 133p.

LIN, M.T.; DIANESE, J.C. A coconut-agar medium for rapid detection of aflatoxin production by Aspergillus spp. Phytopathology, St. Paul, v.66, n.12, p.14661469, 1976.

PITT, J.I. A laboratory guide to common Penicillium species. North Wales : CSIRO-Division of Food Processing, 1991. 187p.

POZZI, C.R. Milho pós-colheita e armazenado: microbiota fúngica e a ocorrência de micotoxinas. Pirassununga : Universidade de São Paulo, 1993. 165p. Dissertação de Mestrado.

RANJAN, K.S.; SINHA, A.K. Occurrence of mycotoxigenic fungi and mycotoxins in animal feed from Bihar, India. Journal of the Science of Food and Agriculture, Essex, v.56, p.39-47, 1991.

SAMSON, R.A.; HOEKSTRA, E.S.; FRISVAD, J.C.; FILTENBORG, O. Introduction to food-borne fungi. 4.ed. Baar : Centralalbureau voor Schimmelcultures, 1995. p.3-235.

SAUER, D.B.; STOREY, C.L.; ECKER, O.; FULK, D.W Fungi in U.S. export wheat and corn. Phytopathology, St. Paul, v.72, n.11, p.1449-1452, 1982

SCHMIDT, R.; MONDANI, J.; ZIEGENHAGEN, E.; DOSE, K. High-performance liquid chromatography of the mycotoxins sterigmatocystin and its application to the analysis of mouldy rice for sterigmatocystin. Journal of Chromatography, Amsterdam, v.207, p.435-438, 1981.

SINGH, K.; FRISVAD, J.C.; THRANE, U.; MATHUR, S.B. An illustrated manual on identification of some seed-borne Aspergilli, Fusaria, Penicillia and their mycotoxins. Lyngby : Institute of Seed Pathology for Developing Countries, 1991. 132p.

SINHA, K.K. Incidence of mycotoxins in maize grains in Bihar State, India. Food Additives and Contaminants, Hants, v.7, n.1, p.55-61, 1990.

SMITH, J.E.; MOSS, M.O. Mycotoxins: formation, analysis and significance. Chichester : J. Wiley, 1985. $147 \mathrm{p}$.

VALLADARES, L.L. Micotoxinas y micotoxicosis. I. Afs. Alimentos, Santiago, v.10, n.3, p.32-40, 1985. 